\title{
Evaluation of Serum Levels of Procalcitonin and C-Reactive Protein as Prognostic Indicators in Burns
}

\author{
Aparna Sinha ${ }^{1}$ Mukesh Kumar Sharma ${ }^{2}$ Komal Tripathi ${ }^{2} \quad$ Nandini Duggal $^{3}$ Vinay Kumar Tiwari ${ }^{4}$ \\ ${ }^{1}$ Department of Plastic Surgery, Rajendra Institute of Medical \\ Sciences, Ranchi, Jharkhand, India \\ 2Department of Burns, Plastic and Reconstructive Surgery, PGIMER \\ and Dr. R. M. L. Hospital, New Delhi, India \\ ${ }^{3}$ Department of Microbiology, PGIMER and Dr. R. M. L. Hospital, \\ New Delhi, India \\ ${ }^{4}$ Department of Burns, Plastic and Reconstructive Surgery, VMMC \\ and Safdarjung Hospital, New Delhi, India \\ Address for correspondence Aparna Sinha, MS, MCh, Department \\ of Plastic Surgery, Rajendra Institute of Medical Sciences, \\ Bariatu, Ranchi, Jharkhand - 834009, India \\ (e-mail: aparnalotusinha@gmail.com). \\ Indian J Plast Surg 2021;54:308-313.
}

\begin{abstract}
Background Burn is a leading cause of fatality in a developing country. C-reactive protein levels (CRP) and procalcitonin (PCT) can be prognostic indicators for the burn patients' mortality.

Aim To assess serial levels of serum PCT and serum CRP as prognostic indicators in burns.

Patient and Methods In patients admitted with burns, alternate-day serum PCT and CRP were measured from the time of admission until the time of discharge or until survival. The change in trends of CRP and PCT serum levels were studied, and it was then correlated with mortality among these burn patients.

Results The first-day value of serum PCT $>1772 \mathrm{pg} / \mathrm{mL}$ and serum CRP $>71 \mathrm{mg} / \mathrm{mL}$

Keywords

- burns

- blood

- C-reactive pro-

tein (CRP)

- procalcitonin (PCT)

- mortality or any value of serum PCT $>2163 \mathrm{pg} / \mathrm{mL}$ and of serum CRP $>90 \mathrm{mg} / \mathrm{L}$ indicate a poor prognosis in burns.

Conclusions The day- 1 values of PCT and CRP were significantly higher in nonsurvivors than survivors in burns. The increasing trends of serum PCT and CRP levels are independent predictors of mortality in burns requiring prompt intervention. Rising PCT and CRP level denote poor prognosis in burns with an increased likelihood of death by 4.5 and 23.6 times, respectively.
\end{abstract}

\section{Introduction}

Burns are a major public health concern around the world, causing substantial morbidity and mortality. Various scoring systems used for prognosis are Baux score, APACHE-II, Roi index and a body shape index (ABSI). ${ }^{1}$ Most of the tools used for evaluating burn prognosis include age, total burn surface area (TBSA), and inhalational injury; hence, they are insufficient to predict changes in patient's prognosis during the hospital stay and cannot predict prognosis in patients of similar cohorts. It is imperative to find out criteria that can predict mortality on the first day and during the hospital stay to take necessary corrective measures, in order to improve prognosis. Serum procalcitonin (PCT) and C-reactive protein (CRP) are already being used for predicting infection, sepsis, and ICU mortality, but very few have studied their use in burn mortality. ${ }^{2-5}$ Hence, there is a need to study the effect of day-one PCT and CRP trends on burn mortality. published online

September 2, 2021
DOI https://doi.org/

$10.1055 / \mathrm{s}-0041-1734574$

ISSN 0970-0358

\section{(C) 2021. Association of Plastic Surgeons of India.}

This is an open access article published by Thieme under the terms of the Creative Commons Attribution-NonDerivative-NonCommercial-License, permitting copying and reproduction so long as the original work is given appropriate credit. Contents may not be used for commercial purposes, or adapted, remixed, transformed or built upon. (https://creativecommons.org/licenses/by-nc-nd/4.0/).

Thieme Medical and Scientific Publishers Pvt. Ltd. A-12, 2nd Floor, Sector 2, Noida-201301 UP, India 
The assessment of mortality risk in burn patients aids in the development of a management protocol that improves prognosis. ${ }^{6}$ PCT is a stable marker for burn inflammation, which is not affected by immunodeficiency states, neutropenia, and steroid and nonsteroid anti-inflammatory drugs (NSAIDs). ${ }^{7.8} \mathrm{CRP}$ is an acute-phase reactant, which is a surrogate for proinflammatory interleukin (IL-6). ${ }^{9.10}$ We hypothesized that serum levels of PCT and CRP are reliable prognostic indicators in burns. Testing the hypothesis helped determine trends and levels at which we require intervention in burns to prevent a fatal outcome.

\section{Patients and Methods}

This prospective observational study, conducted from February 1, 2018, to August 31, 2019, consisted of 51 patients. We did the study after obtaining approval from the institutional ethical committee and obtaining fully informed written consent.

Inclusion criteria-age between 18 to 60 years, admitted within 48 hours of thermal burn injury of 20 to $60 \%$, and total burn surface area (TBSA) without inhalational injury.
Exclusion criteria-pregnancy, patients with associated injuries or comorbidities.

Study procedure-day 1 onward ( 24 hours to 48 hours of burn injury), we estimated alternate-day serum PCT and CRP until patient death or discharge.

Serum PCT and CRP level was determined by commercially available ELISA test kit (human PCT ELISA, human CRP ELISA), available from BioVendor - Laboratorni medicina a.s., following manufacture's instruction manual. Samples were diluted three times in dilution buffer. A microplate reader was used to read the absorbance of each well within 5 minutes, ideally at $450 \mathrm{~nm}$ with a reference filter of $630 \mathrm{~nm}$. The concentration of serum PCT and CRP was directly proportional to the absorbance and was determined using a standard curve of absorbance value. The value obtained was then multiplied by sample dilution factor 3 to get the actual value.

Average serum concentration taken as a reference value are serum PCT: $<0.5 \mathrm{ng} / \mathrm{mL}$; serum CRP: $<3 \mathrm{mg} / \mathrm{dl}^{11}$

Day 1 and then alternate-day serum PCT and serum CRP levels of all the patients included in the study were measured during their hospital stay. Patients were classified into two groups: nonsurvivors and survivors (discharged). The values and trend of change in of serum PCT and serum CRP were

Table 1 Comparison of survivors and nonsurvivors

\begin{tabular}{|c|c|c|c|}
\hline & \multicolumn{2}{|l|}{ Mean \pm SD } & \multirow[t]{2}{*}{$p$-value } \\
\hline & Nonsurvivor & Survivor & \\
\hline \multicolumn{4}{|c|}{ Patient demography } \\
\hline Age & $38.53 \pm 12.11$ & $29.72 \pm 7.84$ & 0.012 \\
\hline TBSA & $51.67 \pm 8.55$ & $31.81 \pm 10.21$ & $<0.0001$ \\
\hline Hospital stay & $8.87 \pm 6.48$ & $9.08 \pm 5.48$ & 0.574 \\
\hline \multicolumn{4}{|c|}{ Serial levels of mean PCT } \\
\hline PCT1 & $2637.87 \pm 1505.45$ & $1376.58 \pm 1015.12$ & 0.0002 \\
\hline РСТ3 & $2293.36 \pm 659.07$ & $792.78 \pm 639.66$ & $<0.0001$ \\
\hline РCT5 & $2227 \pm 886.25$ & $562.71 \pm 425.13$ & $<0.0001$ \\
\hline PCT7 & $1790.75 \pm 693.42$ & $553.1 \pm 374.03$ & 0.0001 \\
\hline РСТ9 & $1865 \pm 717.64$ & $421.2 \pm 313.69$ & 0.0005 \\
\hline PCT11 & $1988.67 \pm 520.89$ & $363 \pm 246.07$ & 0.001 \\
\hline PCT15 & $2048 \pm 385.91$ & $328.17 \pm 234.28$ & 0.020 \\
\hline PCT17 & $2072.5 \pm 38.89$ & $320 \pm 298.6$ & 0.05 \\
\hline \multicolumn{4}{|c|}{ Serial levels of mean CRP } \\
\hline CRP1 & $91.33 \pm 7.09$ & $56.92 \pm 24.38$ & $<0.0001$ \\
\hline CRP3 & $96.79 \pm 2.61$ & $51.39 \pm 25.49$ & $<0.0001$ \\
\hline CRP7 & $91.25 \pm 3.81$ & $56.71 \pm 23.28$ & 0.0001 \\
\hline CRP9 & $87.33 \pm 8.21$ & $51.6 \pm 20.78$ & 0.002 \\
\hline CRP11 & $83.83 \pm 11.99$ & $47.17 \pm 18.68$ & 0.002 \\
\hline CRP13 & $86 \pm 7.55$ & $56 \pm 13.04$ & 0.021 \\
\hline CRP15 & $75 \pm 10.15$ & $42.67 \pm 12.09$ & 0.020 \\
\hline CRP17 & $76 \pm 2.83$ & $41 \pm 12.7$ & 0.05 \\
\hline \multicolumn{4}{|c|}{ Pearson coefficient of CRP and PCT trends } \\
\hline PCT trend & $0.4 \pm 0.64$ & $-0.93 \pm 0.1$ & $<0.0001$ \\
\hline CRP trend & $-0.01 \pm 0.88$ & $-0.82 \pm 0.41$ & $<0.0001$ \\
\hline
\end{tabular}

Abbreviations: CRP, C-reactive protein; PCT, procalcitonin; SD, standard deviation; TBSA, total burn surface area. 
compared in both the groups. The factors that affect mortality in this study are alternate-day serum PCT level, alternate-day serum CRP level, age, TBSA, and hospital stay.

The smallest sample size required with a $5 \%$ level of significance was 37 , with the required power of study being $80 \%$. We considered the sample size of 50 to decrease the error.

\section{Statistical Analysis}

The data and variables were entered into MS Excel spreadsheet, and SPSS 21.0 was used for the statistical analysis. Pearson correlation coefficient was used to assess PCT and CRP's correlation with a time interval to assess PCT and CRP trends. The cutoff values for serum PCT and serum CRP associated with risk of mortality were analyzed, utilizing the receiver operating characteristic (ROC) curve. Logistic regression and Cox proportional hazard regression were used to determine the association of risk factors with mortality. $p$-value $<0.05 \%$ was considered as statistically significant.

\section{Results}

\section{Comparison of Groups}

Out of 51 patients enrolled, 36 patients were discharged in a stable condition, and 15 patients expired, forming the survivor and nonsurvivor groups, respectively. Mean age and TBSA were significantly higher in nonsurvivor than survivors. Mean hospital stay was approximately nine days in both groups. Serum PCT and CRP were observed to be significantly higher in nonsurvivors than survivors during the study ( - Table 1 and - Fig. 1 ).

\section{Trends and Correlations}

Survivors had significant negative PCT and CRP trends with the Pearson correlation coefficient of -0.93 and -0.82 , respectively. Nonsurvivors had a significant positive PCT trend with a Pearson correlation coefficient of 0.4. Nonsurvivors had a nonsignificant negative CRP trend with a Pearson correlation coefficient of - 0.01 (-Tables 1, 2 and - Fig. 1). PCT and CRP's trend difference in nonsurvivor and survivor groups were highly significant ( $p$-value $<0.0001$ ) ( - Table 1 ).

First-day values of PCT and CRP correlated to TBSA with the Pearson coefficient of 0.54 and 0.87 , respectively ( $p$-value $<0.001)$. PCT1 correlated to age with Pearson coefficient of 0.539 ( $p$-value $<0,001$ ). CRP1 correlated to the hospital stay with a Pearson coefficient of 0.394 ( $p$-value 0.004 ) (-Table 2).

\section{ROC}

The ROC curve was used to estimate the cutoff point of various risk factors in predicting mortality by taking their day one value into account. Out of all variables, TBSA was found to be the best predictor of mortality on day 1 . Serum PCT1 over $1772 \mathrm{pg} / \mathrm{mL}$ and CRP1 above $71 \mathrm{mg} / \mathrm{L}$ show poor prognosis, with the Youden index being 0.66 and 0.7222 , respectively.

(-Table 3).

The ROC curve for PCT and CRP's highest value were plotted during the study to predict mortality, which denotes a poor prognosis. Any reading in a patient for PCT over $2163 \mathrm{pg} / \mathrm{mL}$ was significant, with an are under curve (AUC) of 0.921 . Youden index of PCTmax was 0.83 . Any reading in a patient for CRP over $90 \mathrm{mg} / \mathrm{L}$ was significant, with an AUC of 0.912. Youden index of CRPmax was 0.81 (-Table 3).

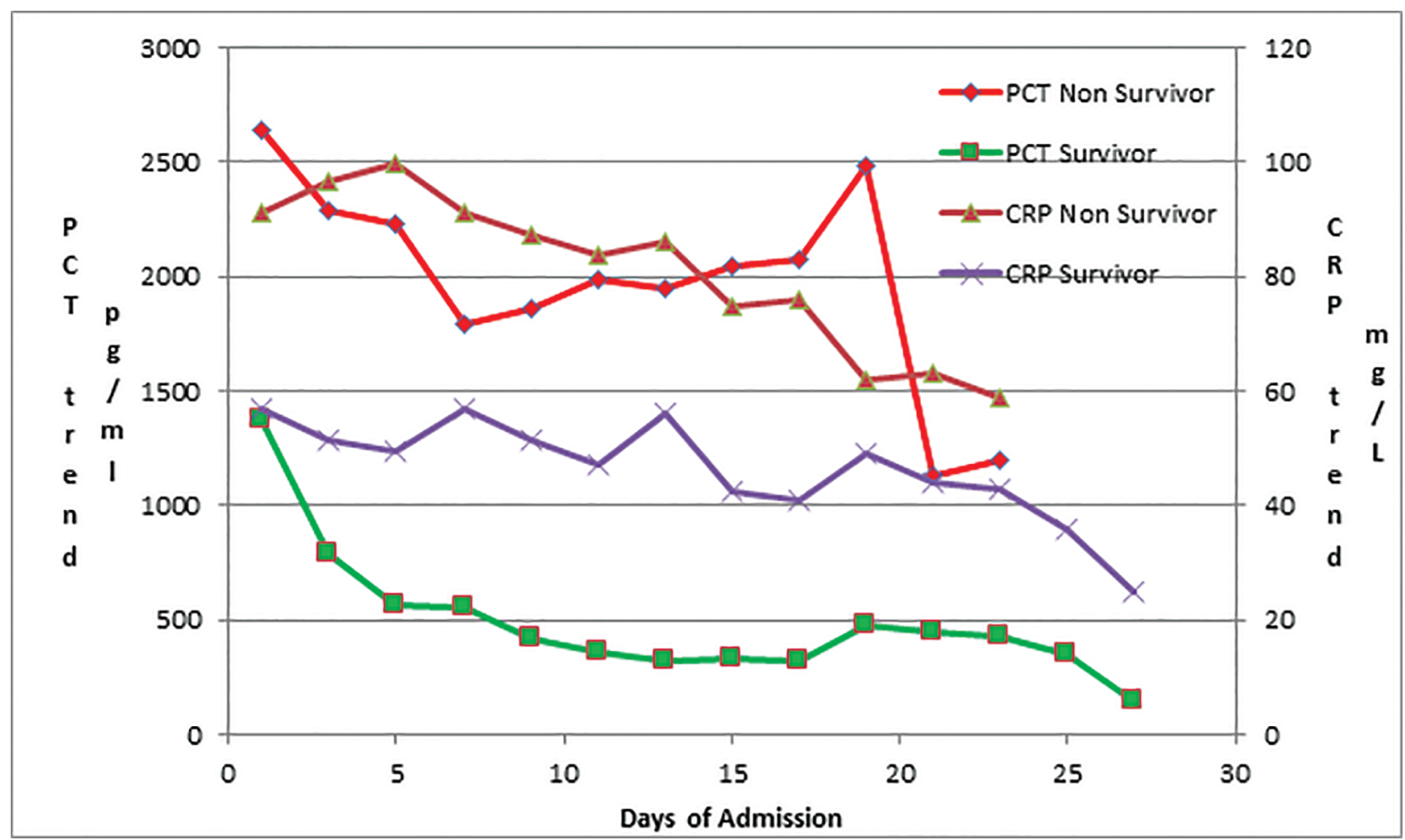

Fig. 1 Mean values of PCT and CRP during the hospital stay in nonsurvivors and survivors. 
Table 2 Pearson correlation coefficient among the variables

\begin{tabular}{|l|l|l|l|l|}
\hline \multicolumn{2}{|c|}{ Variables } & $95 \%$ Cl for mean & Pearson correlation coefficient & $p$-value \\
\hline PCT trend & Nonsurvivor & 0.0305 to 0.77 & 0.4 & 0.036 \\
\hline PCT trend & Survivor & -0.964 to -0.896 & -0.93 & $<0.0001$ \\
\hline CRP trend & Nonsurvivor & -0.542 to 0.522 & -0.01 & 0.968 \\
\hline CRP trend & Survivor & -0.961 to -0.679 & -0.82 & $<0.0001$ \\
\hline
\end{tabular}

Abbreviations: $\mathrm{Cl}$, confidence interval; CRP, C-reactive protein; $\mathrm{PCT}$, procalcitonin.

Table 3 The receiver operating characteristic curve was used to determine the cutoff point of parameters for predicting mortality

\begin{tabular}{|l|l|l|l|l|l|l|l|}
\hline & (AUC) & Standard error & $95 \%$ CI & $p$-value & Cutoff & Sensitivity & Specificity \\
\hline Age & 0.723 & 0.0919 & 0.580 to 0.839 & 0.0152 & $>35$ & 66.67 & 83.33 \\
\hline TBSA & 0.919 & 0.0394 & 0.808 to 0.977 & $<0.0001$ & $>45$ & 80 & 88.89 \\
\hline Hospital stay & 0.55 & 0.103 & 0.404 to 0.690 & 0.6263 & $\leq 3$ & 26.67 & 97.22 \\
\hline PCT1 & 0.835 & 0.0552 & 0.705 to 0.924 & $<0.0001$ & $>1772$ & 93.33 & 72.22 \\
\hline CRP1 & 0.87 & 0.0493 & 0.747 to 0.948 & $<0.0001$ & $>71$ & 100 & 72.22 \\
\hline Max CRP & 0.912 & 0.0364 & 0.799 to 0.973 & $<0.0001$ & $>90$ & 100 & 80.56 \\
\hline Max PCT & 0.921 & 0.0374 & 0.811 to 0.978 & $<0.0001$ & $>2163$ & 100 & 83.33 \\
\hline
\end{tabular}

Abbreviations: AUC, area under curve; $\mathrm{Cl}$, confidence interval; CRP, C-reactive protein; $\mathrm{PCT}$, procalcitonin; TBSA, total burn surface area.

Table 4 Logistic and Cox regression

\begin{tabular}{|c|c|c|c|c|c|c|}
\hline & \multirow[t]{2}{*}{ B } & \multirow[t]{2}{*}{ Standard error } & \multirow[t]{2}{*}{ Odds ratio } & \multicolumn{2}{|c|}{$95 \% \mathrm{Cl}$ for odds ratio } & \multirow[t]{2}{*}{$p$-value } \\
\hline & & & & Lower & Upper & \\
\hline \multicolumn{7}{|c|}{ Univariate logistic regression on day 1} \\
\hline Age & 0.093 & 0.035 & 1.097 & 1.023 & 1.176 & 0.009 \\
\hline TBSA & 0.170 & 0.045 & 1.185 & 1.085 & 1.294 & 0.0002 \\
\hline Hospital Stay & -0.007 & 0.055 & 0.993 & 0.892 & 1.106 & 0.901 \\
\hline PCT1 & 0.001 & 0.000 & 1.001 & 1.000 & 1.002 & 0.009 \\
\hline CRP1 & 0.096 & 0.032 & 1.101 & 1.034 & 1.171 & 0.002 \\
\hline \multicolumn{7}{|c|}{ Multivariate logistic regression on day 1} \\
\hline Age & 0.087 & 0.053 & 1.091 & 0.983 & 1.212 & 0.102 \\
\hline TBSA & 0.149 & 0.065 & 1.161 & 1.022 & 1.319 & 0.022 \\
\hline PCT1 & 0.000 & 0.000 & 1.000 & 0.999 & 1.001 & 0.657 \\
\hline \multirow[t]{3}{*}{ CRP1 } & 0.037 & 0.040 & 1.037 & 0.959 & 1.123 & 0.362 \\
\hline & \multirow[t]{2}{*}{ B } & \multirow[t]{2}{*}{ S.E. } & \multirow[t]{2}{*}{ Hazard ratio } & \multicolumn{2}{|c|}{$95.0 \% \mathrm{Cl}$ for the hazard ratio } & \multirow[t]{2}{*}{$p$-value } \\
\hline & & & & Lower & Upper & \\
\hline \multicolumn{7}{|c|}{ Univariate Cox regression } \\
\hline Age & 0.055 & 0.022 & 1.057 & 1.012 & 1.103 & 0.012 \\
\hline TBSA & 0.102 & 0.033 & 1.108 & 1.038 & 1.182 & 0.002 \\
\hline PCT trend & 2.596 & 0.614 & 13.405 & 4.020 & 44.698 & $<0.0001$ \\
\hline CRP trend & 3.038 & 0.751 & 20.863 & 4.784 & 90.982 & 0.0001 \\
\hline \multicolumn{7}{|c|}{ Multivariate Cox regression } \\
\hline Age & 0.009 & 0.028 & 1.009 & 0.955 & 1.066 & 0.758 \\
\hline TBSA & 0.026 & 0.039 & 1.027 & 0.950 & 1.109 & 0.505 \\
\hline PCT trend & 1.505 & 0.728 & 4.503 & 1.081 & 18.759 & 0.039 \\
\hline CRP trend & 3.165 & 1.217 & 23.685 & 2.181 & 257.257 & 0.009 \\
\hline
\end{tabular}

Abbreviations: $\mathrm{Cl}$, confidence interval; CRP, C-reactive protein; $\mathrm{PCT}$, procalcitonin; TBSA, total burn surface area.

\section{Logistic Regression and Cox Regression}

Using univariate logistic regression analysis, and taking mortality as a dependent variable, age, TBSA, PCT and CRP were the significant factors associated with increased risk on day 1 . Increasing values of age, TBSA, PCT1 and CRP1 were associated with an increase in mortality risk. Only TBSA was 
found to be an independent risk factor for mortality on day 1 in a multivariate logistic regression study (-Table 4 ).

The risk of time point mortality was calculated using univariate and multivariate Cox proportional hazard regression. An increasing trend of PCT and CRP was associated with a significant increase in the risk of mortality by 13.4 and 20.8 times, respectively ( $p$-value $<0.001$ and $0.0001 \%$ ), compared with patients who did not have increasing trends of PCT and CRP ( - Table 4). On multivariate Cox proportional hazard regression analysis, only PCT and CRP trend were independent risk factors associated with mortality, which increased by 4.5 and 23.6 times, respectively ( $p$-value 0.039 and 0.009 ), compared with patients who did not have increasing trends PCT and CRP ( - Table 4).

\section{Discussion}

Sepsis is a leading cause of death in burn patients. ${ }^{12}$ The prompt administration of appropriate antimicrobial therapy is the most significant isolated factor for the septic patient's survival, and any hourly delay is correlated with an increase in mortality. ${ }^{13}$ It is also critical to reducing the likelihood of microbial resistance developing. Selecting the appropriate drug to target the microbiological agent, limiting the length of treatment to the absolute minimum to avoid antibiotic resistance, and selective pressure on microorganisms are also essential. ${ }^{14}$ This technique has additional benefits such as fewer prescription side effects, lower treatment rates, and, in most cases, shorter hospital stays. It is critical to identify biomarkers that can predict mortality, so that timely intervention can be initiated to improve prognosis. Serum PCT and CRP are already used to predict infection, sepsis, and ICU mortality, but there has been little research into their use in burn mortality, particularly in Indian scenarios.

PCT and CRP levels were significantly higher in nonsurvivors than in survivors, according to previous studies. ${ }^{15,16,17}$ Barati et al in 2008 found that raised PCT was better indicator of sepsis in burn patients than white blood cell (WBC) counts, erythrocyte sedimentation rate (ESR) and CRP. ${ }^{15}$ For burn patients with serum PCT $\geq 2 \mathrm{ng} / \mathrm{mL}$, the risk for mortality was 3.163 times more than those with < $2 \mathrm{ng} / \mathrm{mL}^{17}{ }^{17}$ There is no correlation between initial PCT levels (at admission) and TBSA, but the peak level of PCT correlated with TBSA. ${ }^{18}$ CRP level was directly proportional to the TBSA involved and depth of burns. ${ }^{19}$ CRP levels were normal at admission, peaked at 48 hours, and started to reduce by the sixth day postburn. The CRP production response was greater and prolonged when associated with infections. ${ }^{19}$ The sequential estimation of CRP is helpful in the management of scald burns in children. ${ }^{19}$

In our study, higher values of PCT1 and CRP1 were associated with an increased risk of mortality. Increasing trends in PCT and CRP denote increased chances of mortality (-Tables 1, 4). Higher PCT1 and CRP1 were found to be associated with higher TBSA. Our study also showed that nonsurvivors had higher average PCT and CRP levels. The higher value of PCT and CRP on day 1 is associated with an increase in mortality. Rising trends of PCT and CRP denote poor prognosis in burn patients, and the likelihood of death increases by 4.5 and 23.6 times, respectively. For every 1 picogram $/ \mathrm{mL}$ increase in serum PCT1, the mortality is increased by $0.1 \%$. For every $1 \mathrm{microgram} / \mathrm{mL}$ increase in serum CRP1, the mortality is increased by $0.01 \%$. On day 1 , higher levels of age, TBSA, PCT1, and CRP1 were associated with an increase in mortality risk. Only TBSA, however, was discovered to be an independent risk factor for mortality on day 1. PCT1 and CRP1 were found to correlate with TBSA. As a result, more research is needed to determine the effect of TBSA on PCT1 and CRP1 and their impact on mortality.

Thus, based on the current study and the previous studies, it is possible to conclude that both physical and laboratory investigations are relevant for burn prognosis. These findings can be used to prognosticate the patients and modify the management.

Serum PCT1 and CRP1 and the increasing trend in serum PCT and CRP levels can be used not only for the prognostication of burn mortality, but also monitoring patients' response to the management protocol or in deciding if there is any need for change in management plan. Hence, this study shows that not only absolute value on day 1 of admission but trend is also important in prognostication in burns. A larger sample size study is needed to validate the results. Further studies are warranted to examine the role of various interventions, in order to improve the prognosis and their relation with PCT and CRP levels.

\section{Conclusions}

In patients with burn injuries, rising trends of serum PCT and CRP values are associated with poor prognosis. Any value of serum PCT > $2163 \mathrm{pg} / \mathrm{mL}$ and serum CRP > $90 \mathrm{mg} / \mathrm{L}$ during hospitalization indicates poor prognosis with sensitivity $100 \%$ and specificity of $80.56 \%$ and $83.33 \%$, respectively, and the likelihood of death increasing by 4.5 and 23.6 times, respectively. The trend of change in serum values of PCT and CRP can be used for prognostication of mortality and patient's response to treatment.

\section{Declaration}

The study is in accordance with the ethical standards of the responsible committee on human experimentation (institutional or regional) and with the Helsinki Declaration of 1975 , as revised in 2000 .

\section{Ethics Approval and Consent to Participate}

Duly informed consent was obtained in all the cases.

The institutional ethics committee approved the study.

\section{Funding Source}

None.

\section{Conflict of Interests}

None declared 


\section{References}

1 Tobiasen J, Hiebert JM, Edlich RF. The abbreviated burn severity index. Ann Emerg Med 1982;11(5):260-262

2 Bargues L, Chancerelle Y, Catineau J, Jault P, Carsin H. Evaluation of serum procalcitonin concentration in the ICU following severe burn. Burns 2007;33(7):860-864

3 Neely AN, Fowler LA, Kagan RJ, Warden GD. Procalcitonin in pediatric burn patients: an early indicator of sepsis? J Burn Care Rehabil 2004;25(1):76-80

4 Li Q Gong X. Clinical significance of the detection of procalcitonin and C-reactive protein in the intensive care unit. Exp Ther Med 2018;15(5):4265-4270

5 Meng FS, Su L, Tang YQ, Wen Q, Liu YS, Liu ZF. Serum procalcitonin at the time of admission to the ICU as a predictor of shortterm mortality. Clin Biochem 2009;42(10-11):1025-1031

6 Ryan CM, Schoenfeld DA, Thorpe WP, Sheridan RL, Cassem EH, Tompkins RG. Objective estimates of the probability of death from burn injuries. N Engl J Med 1998;338(6):362-366

7 Schneider HG, Lam QT. Procalcitonin for the clinical laboratory: a review. Pathology 2007;39(4):383-390

8 Mann EA, Wood GL, Wade CE. Use of procalcitonin for the detection of sepsis in the critically ill burn patient: a systematic review of the literature. Burns 2011;37(4):549-558

9 Uzzan B, Cohen R, Nicolas P, Cucherat M, Perret GY. Procalcitonin as a diagnostic test for sepsis in critically ill adults and after surgery or trauma: a systematic review and meta-analysis. Crit Care Med 2006;34(7):1996-2003

10 Ahuja RB, Bhattacharya S, Rai A. Changing trends of an endemic trauma. Burns 2009;35(5):650-656

11 Ahuja RB, Bhattacharya S, Rai A. Changing trends of an endemic trauma. Burns 2009;35(5):650-656
12 Sharma BR, Harish D, Singh VP, Bangar S. Septicemia as a cause of death in burns: an autopsy study. Burns 2006;32(5):545-549

13 Kumar A, Roberts D, Wood KE, et al. Duration of hypotension before initiation of effective antimicrobial therapy is the critical determinant of survival in human septic shock. Crit Care Med 2006;34(6):1589-1596

14 Bone RC, Balk RA, Cerra FB, et al. The ACCP/SCCM Consensus Conference Committee. American College of Chest Physicians/Society of Critical Care Medicine. Definitions for sepsis and organ failure and guidelines for the use of innovative therapies in sepsis. Chest 1992;101(6):1644-1655

15 Barati M, Alinejad F, Bahar MA, et al. Comparison of WBC, ESR, CRP and PCT serum levels in septic and non-septic burn cases. Burns 2008;34(6):770-774

16 Piroglu DI, Tulgar S, Piroglu MD, et al. Do early procalcitonin levels aid in predicting mortality in burn patients? Int J Clin Exp Med 2016;9(3):6497-6503

17 Kim HS, Yang HT, Hur J, et al. Procalcitonin levels within 48 hours after burn injury as a prognostic factor. Ann Clin Lab Sci 2012;42(1):57-64

18 von Heimburg D, Stieghorst W, Khorram-Sefat R, Pallua N. Procalcitonin-a sepsis parameter in severe burn injuries. Burns 1998;24(8):745-750

19 Pruchniewski D, Pawlowski T, Morkowski J, Mackiewicz S. C-reactive protein in management of children's burns. Ann Clin Res 1987;19(5):334-338 